\title{
Management of Low Birth Weight in Canine and Feline Species: Breeder Profiling
}

\author{
Amélie Mugnier ${ }^{1, *} \mathbb{( \mathbb { C }}$, Sylvie Chastant ${ }^{1}$, Claude Saegerman $^{2}{ }^{\mathbb{D}}$, Virginie Gaillard ${ }^{3}$, Aurélien Grellet ${ }^{1}$ \\ and Hanna Mila ${ }^{1}$
}

check for updates

Citation: Mugnier, A.; Chastant, S.; Saegerman, C.; Gaillard, V.; Grellet, A.; Mila, H. Management of Low Birth Weight in Canine and Feline Species: Breeder Profiling. Animals 2021, 11, 2953. https://doi.org/ $10.3390 /$ ani11102953

Academic Editor: Cesare Castellini

Received: 29 July 2021

Accepted: 9 October 2021

Published: 13 October 2021

Publisher's Note: MDPI stays neutral with regard to jurisdictional claims in published maps and institutional affiliations.

Copyright: (c) 2021 by the authors. Licensee MDPI, Basel, Switzerland. This article is an open access article distributed under the terms and conditions of the Creative Commons Attribution (CC BY) license (https:// creativecommons.org/licenses/by/ $4.0 /)$.
1 NeoCare, Université de Toulouse, ENVT, CEDEX 03, 31076 Toulouse, France; sylvie.chastant@envt.fr (S.C.); aurelien.grellet@envt.fr (A.G.); hanna.mila@envt.fr (H.M.)

2 UREAR-ULiège, FARAH, Faculté de Médecine Vétérinaire, Université de Liège, 4000 Liège, Belgium; claude.saegerman@ulg.ac.be

3 Royal Canin, 650 Avenue de la Petite Camargue, 30470 Aimargues, France; virginie.gaillard@royalcanin.com * Correspondence: amelie.mugnier@envt.fr

Simple Summary: Mortality rate in puppies and kittens over the first two months of age is high, estimated at around $20 \%$. Low birth weight has been identified as a major risk factor for neonatal mortality in these species. Using an online questionnaire, we explored perceptions and management practices of breeders regarding newborns at low birth weight. Three different profiles were identified among 649 breeders. The first one included mainly dog and cat breeders who weighed newborns and monitored their suckling by the dam (controlled suckling) but did not warm them. The second group consisted of breeders of both species who did not weigh puppies or kittens to identify low birth weight or to monitor their weight afterwards. The third and final group included mostly cat breeders who routinely weighed neonates as in the first group, but who used artificial feeding rather than controlled suckling. This better knowledge of the management of puppies and kittens at high risk of neonatal mortality in the field provides the basis to establish guidelines to increase their chances of survival.

Abstract: Low birth weight (LBW) has been identified as a major risk factor for neonatal mortality in many species. The aim of this survey was to determine the profiles of canine and feline breeders concerning their perceptions of, and management practices relating to, LBW individuals. An anonymous online survey was addressed to French cat and dog breeders in September 2019 via social networks. Multiple correspondence analysis and hierarchical clustering were used to explore breeders' profiles. Three clusters were identified among the 649 breeders included in this analysis. Cluster 1 (49\%) included dog and cat breeders who weighed newborns (and thus identified LBW) and controlled nursing by the dam (controlled suckling) but did not warm them up. Cluster 2 breeders (21\%) of both species did not weigh puppies or kittens to identify LBW or to monitor the evolution of their weight afterwards. Cluster $3(30 \%)$ including mostly cat breeders who weighed neonates routinely as in Cluster 1, but they practiced artificial feeding rather than controlled suckling. This survey provides a basis for better understanding of perceptions and practices regarding LBW puppies and kittens. It will be useful to provide guidelines for neonatal management to increase their chances of survival.

Keywords: low birth weight; dog breeder; cat breeder; management; perception; survey

\section{Introduction}

Canine and feline newborns face high neonatal mortality (from birth to three weeks of age) with average live-born mortality rates close to $10 \%$ during this period [1-3]. Appropriate management of kittens and puppies together with the identification of at-risk newborns in order to improve survival is important for both welfare and economic standpoints.

As in other mammals (e.g., pig, sheep), low birth weight (LBW) is one of the major risk factors of neonatal mortality in puppies and kittens [4-7]. Their limited energy reserves and 
difficulties in suckling to obtain colostrum are, among others, the factors predisposing LBW puppies and kittens to death [8,9]. The breeder plays a pivotal role as early detection of these at-risk newborns followed by the implementation of appropriate management could reduce neonatal mortality, as demonstrated in piglets [10] and lambs [11,12]. Describing and analysing LBW management practices is the first step in reducing the high mortality rates confronting them. In production animals, survey-based studies have been conducted to provide better understanding of newborn management practices, their determinants and their consequences [13-18]. They provide a basis for evaluating current practices and targeting communication and teaching for their improvement. To our knowledge, and despite LBW being a major canine and feline health concern, the management practices and the beliefs of breeders regarding LBW have never been the subject of any scientific study.

The objective of this study was thus, for the first time, to identify canine and feline breeder profiles regarding LBW management (i.e., groups with similar management practices) based on data collected through a large online survey.

\section{Materials and Methods}

\subsection{Survey Design}

A collaborative meeting was first organised between five veterinarians specialized in carnivore neonatology and 15 French canine and/or feline breeders to explore the management of newborns in their facilities. An online questionnaire was then drafted in French using the software Sphinx iQ 2 (Le Sphinx, Chavanod, France) and pretested by 10 people. The survey was launched in September 2019: the link was sent to dog and cat breeders belonging to the NeoCare network via Facebook and an internal mailing list ( $n=3743$ and $n=910$, respectively). This network is made up of breeders who have voluntarily signed up to receive newsletters about the work of the team. The survey was also shared without our control. At the beginning of the questionnaire, participants were informed about the anonymity and confidentiality of the data they provide, and that by completing the questionnaire they were giving their consent for their answers to be analysed.

Among all the questions included in the survey, only those focusing on canine and feline breeders' practices and perceptions around LBW were selected for this study. After the preprocessing of these questions (Table S1), 10 (Table 1) were used as variables in the statistical analysis. Only breeders with a response for all these 10 questions were retained for the analysis.

Table 1. List of variables and their modalities used for the multivariate explanatory analysis.

\begin{tabular}{|c|c|c|c|c|}
\hline Categories & Questions & Variables & Modalities & Code \\
\hline & Species bred & Species & Dog & Species.Dogs \\
\hline & & & Cat & Species.Cats \\
\hline & & & Dog and cat & Species.Dog ... Cats \\
\hline \multirow[t]{8}{*}{ Perceptions } & Is LBW a risk factor for neonatal mortality? & RiskFactor & Yes & RiskFactor.Yes \\
\hline & & & No & RiskFactor.No \\
\hline & Is LBW frequent? ${ }^{1}$ & Frequent & 1 or 2 & Frequent. 1 or 2 \\
\hline & & & 3 to 5 & Frequent. 3 to 5 \\
\hline & & & 6 to 10 & Frequent. 6 \\
\hline & Is LBW difficult to manage? ${ }^{2}$ & DiffManag & 1 or 2 & DiffManag. 1 or 2 \\
\hline & & & 3 to 5 & DiffManag. 3 to 5 \\
\hline & & & 6 to 10 & DiffManag.6 \\
\hline
\end{tabular}


Table 1. Cont.

\begin{tabular}{ccccc}
\hline Categories & Questions & Variables & Modalities & Code \\
\hline Practices & Which method is used to identify LBW? & Id & Observation & Id.Obs \\
\hline & & & Weighing & Id.Weighing \\
\hline Temperature monitoring of LBW neonates? & TempMonit & Yes & TempMonit.Yes & TempMonit.No \\
\hline Controlled suckling for LBW? & ContrSuckl & Yes & ContrSuckl.Yes \\
\hline Weight monitoring for LBW? & RegWeigh & Yes & ContrSuckl.No \\
\hline & & No & RegWeigh.Yes \\
\hline Warming for LBW? & Warm & Yes & RegWeigh.No \\
\hline Artificial feeding for LBW? & & No & Warm.Yes \\
\hline & ArtiFeed & Yes & No & ArtiFeed.Yes \\
\hline
\end{tabular}

${ }^{1}$ From 1 (extremely rare) to 10 (very frequent); ${ }^{2}$ from 1 (not at all) to 10 (very difficult). LBW: low birth weight.

\subsection{Statistical Analysis}

The statistical analysis of the survey was divided into two steps in view to establishing a typology of breeders with similar practices and perceptions with regard to LBW neonates and their management. First, a multiple correspondence analysis (MCA) was performed to summarize the information contained in the selected set of categorical variables and evaluate the pattern of their relationships. MCA reduces the dimensions of these multivariate data by constructing a small number of uncorrelated synthetic factors (components or dimensions) accounting for most data variability [19]. This descriptive explanatory method also produces graphical displays making it possible to analyse the results. Only the first $n$ dimensions (or components) that attain more than $50 \%$ of the variability explained were kept for interpretation.

For the second stage, the results obtained from MCA were used in a hierarchical cluster analysis (HCA) to place breeders into different classes. The "Euclidean" distance was calculated between the individual breeders based on the first five components selected from the MCA. Then, using Ward's minimum variance method consolidated with the K-means method [20], HCA was used to identify homogenous clusters of breeders and their common characteristics were employed to create the profile of the cluster relating to LBW identification, management practices and perceptions.

Statistical analyses were performed using R software, version 4.0.1 [21] and the "FactomineR" package [22].

\section{Results}

Six hundred and forty-nine of the 674 breeders who participated in the survey were retained for this study (answers for all the questions selected). Most of them were located in France $(n=514 / 649,79 \%$, Figure 1) although three other countries were represented (Belgium, $n=10$; Switzerland, $n=8$; Canada, $n=1$ ). The country of the 116 remaining respondents (18\%) could not be identified. Among the 649 participants, $48 \%$ were cat breeders, $46 \%$ were dog breeders and the remaining $6 \%$ were both dog and cat breeders.

\subsection{Multiple Correspondence Analysis}

Five dimensions were retained for performing the MCA, accounting for a total of $52.3 \%$ of the data dispersion (i.e., variance or inertia). Figure 2 presents the cloud of modalities in the first factorial plane, i.e., with the $\mathrm{x}$ and $\mathrm{y}$ axes representing the first and the second dimensions, respectively. 

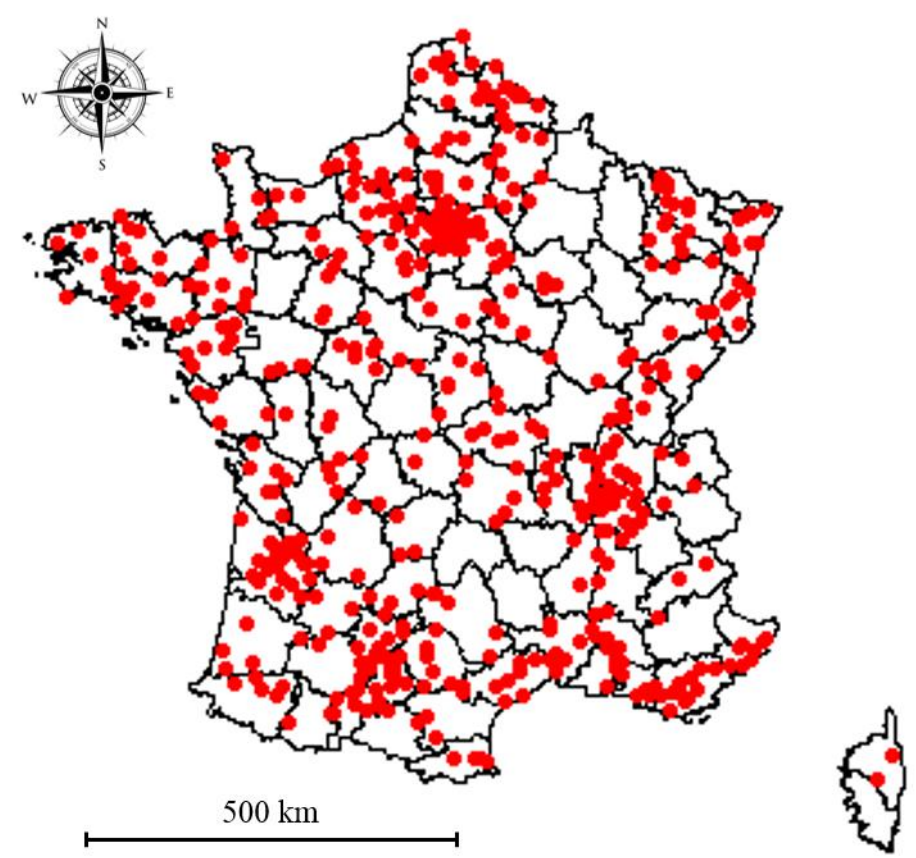

Figure 1. Location of the 528 French breeders who participated in the survey and whose postcode could be identified.

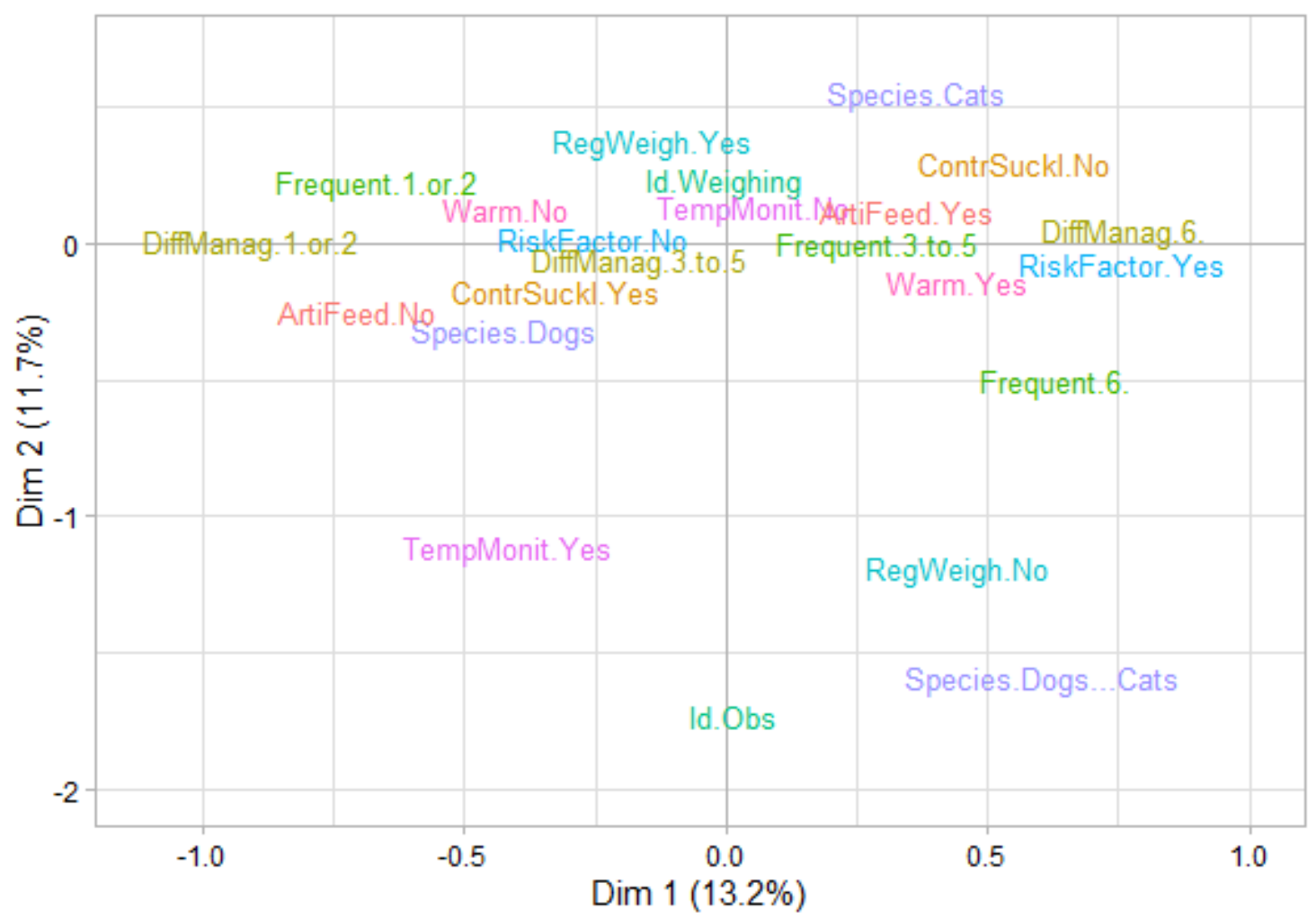

Figure 2. Breeders' characteristics on factorial axes 1 and 2 according to the multiple correspondence analysis (MCA; $n=649$ dog and cat breeders). Legend: Dim 1: dimension 1; Dim 2: dimension 2; RiskFactor.Yes/RiskFactor.No: is low birth weight (LBW) a risk factor for neonatal mortality? Yes/No; Frequent.1 or 2/Frequent.3 to 5/Frequent.6: is LBW frequent? From 1 (extremely rare) to 10 (very frequent); DiffManag.1 or 2/DiffManag.3 to 5/DiffManag.6: is LBW difficult to manage? From 1 (not at all) to 10 (very difficult); Id.Obs/Id.Weighing: which method is used to identify LBW? observation/weighing; TempMonit.Yes/Temp.Monit.No: temperature monitoring of LBW? Yes/No; ContrSuckl.Yes/ContrSuckl.No: controlled suckling for LBW? Yes/No; RegWeigh.Yes/RegWeigh.No: weight monitoring for LBW? Yes/No; Warm.Yes/Warm.No: warming for LBW? Yes/No; ArtiFeed.Yes/ArtiFeed.No: artificial feeding for LBW? Yes/No. 
Figure 3 provides a graphical representation of the multiple correspondence analysis (MCA) results in the form of clouds of individuals according to variables and modalities. The first dimension explained $13.2 \%$ of the total inertia. It opposed breeders who considered LBW as a frequent issue difficult to manage and cat and mixed breeders (positive coordinates) versus breeders for whom LBW is not frequent but easy to manage and dog breeders (negative coordinates). This first axis also opposed cat breeders and mixed breeders versus dog breeders. The use of artificial feeding was also well represented on this axis. The second dimension accounted for $11.7 \%$ of the total inertia. It differentiated breeders who used weighing to identify LBW neonates and who practiced regular weighing for neonate follow-up against those who did not. The species reared on the facility was also well represented on this axis. Finally, breeders who practised controlled suckling and warming for LBW neonates were well represented on the third factorial axis, which represented $10.2 \%$ of the total inertia (Table 2). The correlation ratios (varying between 0 and 1) of the synthesis variables to the original ones, allowed identifying the most structuring variables and are presented in Table 2 .

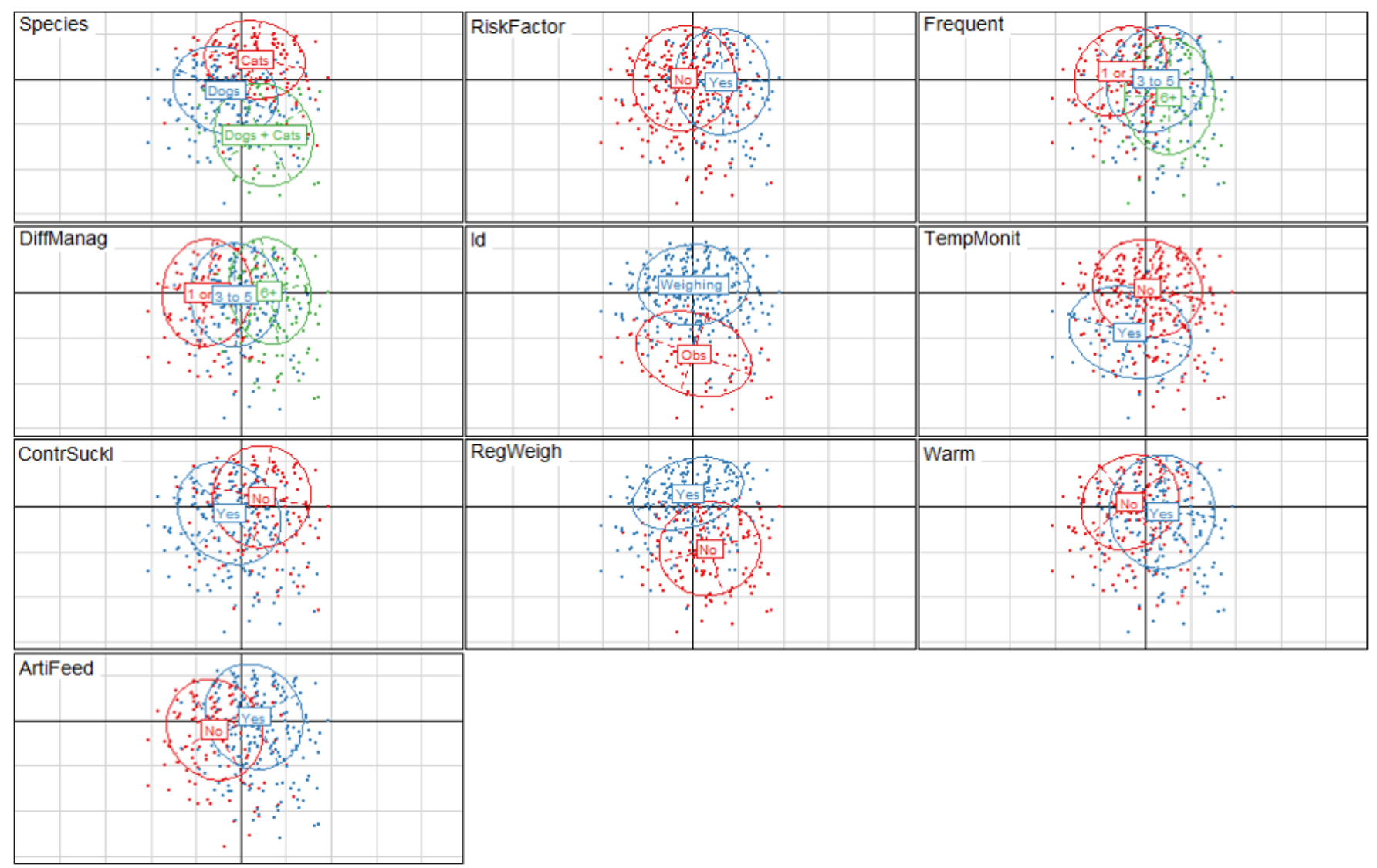

Figure 3. Graphical representation of multiple correspondence analysis (MCA) results based on clouds of individuals according to variables and modalities ( $n=674$ dog and cat breeders). Legend: Dim 1: dimension 1; Dim 2: dimension 2; RiskFactor: is low birth weight (LBW) a risk factor for neonatal mortality? Yes/No; Frequent: is LBW frequent? From 1 (extremely rare) to 10 (very frequent); DiffManag: is LBW difficult to manage? From 1 (not at all) to 10 (very difficult); Id: which method is used to identify LBW? observation/weighing; TempMonit: temperature monitoring of LBW? Yes/No; ContrSuckl: controlled suckling for LBW? Yes/No; RegWeigh: weight monitoring for LBW? Yes/No; Warm: warming for LBW? Yes/No; ArtiFeed: artificial feeding for LBW? Yes/No. 
Table 2. Correlation ratios between the variables and the five dimensions used for the MCA.

\begin{tabular}{cccccc}
\hline Variable & Dim 1 & Dim 2 & Dim 3 & Dim 4 & Dim 5 \\
\hline Artificial feeding for LBW? & 0.24 & 0.03 & 0.06 & 0.07 & 0.16 \\
\hline Controlled suckling for LBW? & 0.18 & 0.05 & 0.29 & 0.25 & 0.05 \\
\hline Is LBW difficult to manage? & 0.40 & $2.5 \times 10^{-3}$ & 0.20 & 0.26 & 0.05 \\
\hline Is LBW frequent? & 0.27 & 0.06 & 0.22 & 0.02 & 0.02 \\
\hline Which method is used to identify LBW? & $2.1 \times 10^{-5}$ & 0.41 & $1.1 \times 10^{-3}$ & 0.22 & $1.8 \times 10^{-4}$ \\
\hline Weight monitoring for LBW? & 0.06 & 0.45 & 0.01 & 0.02 & 0.05 \\
\hline Is LBW a risk factor for neonatal mortality? & 0.19 & $1.6 \times 10^{-3}$ & 0.10 & 0.04 \\
\hline Species bred & 0.17 & 0.35 & 0.02 & 0.22 \\
\hline Temperature monitoring of LBW neonates? & 0.02 & 0.15 & 0.40 & $3.89 \times 10^{-3}$
\end{tabular}

Dim: dimension. Correlation ratios were coloured according to their value: green for values higher than or equal to 0.40 (the most structuring variables for each dimension); yellow for values ranging from 0.20 to 0.40 ; red for values ranging from 0.10 to 0.20 (included) and white for values lower than 0.10 .

\subsection{Typology of Breeders}

In total, three profiles of breeders regarding LBW identification, management and perception were identified and are represented in Figure 4. Detailed behaviours in each cluster are presented in Table 3.

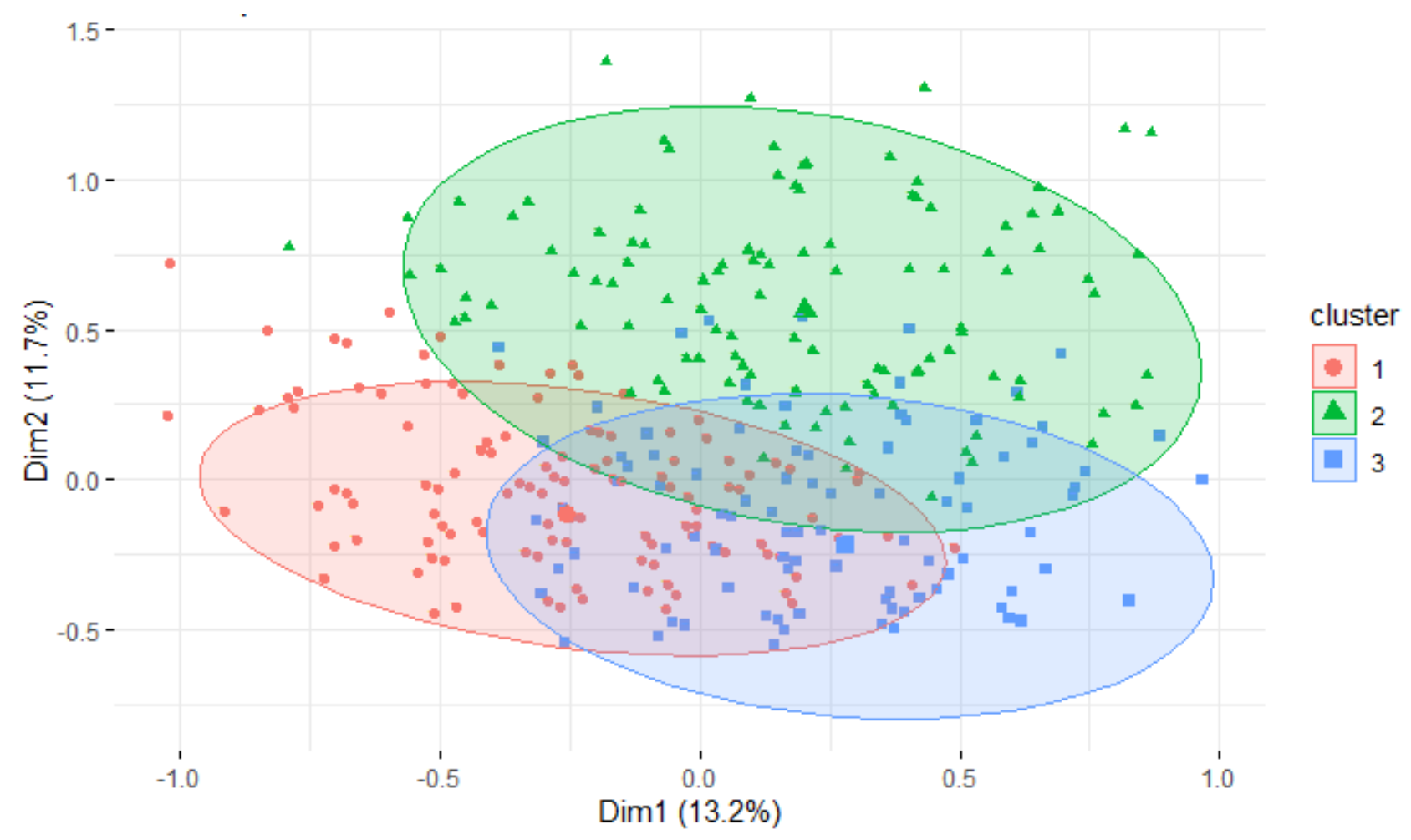

Figure 4. Representation of the three clusters of canine and feline breeders on the first factorial plane $(n=649$ dog and cat breeders). Legend: Dim 1: dimension 1; Dim 2: dimension 2. 
Table 3. Distribution of the modalities in the three clusters identified through multiple correspondence and hierarchical cluster analyses with notation of significant variation.

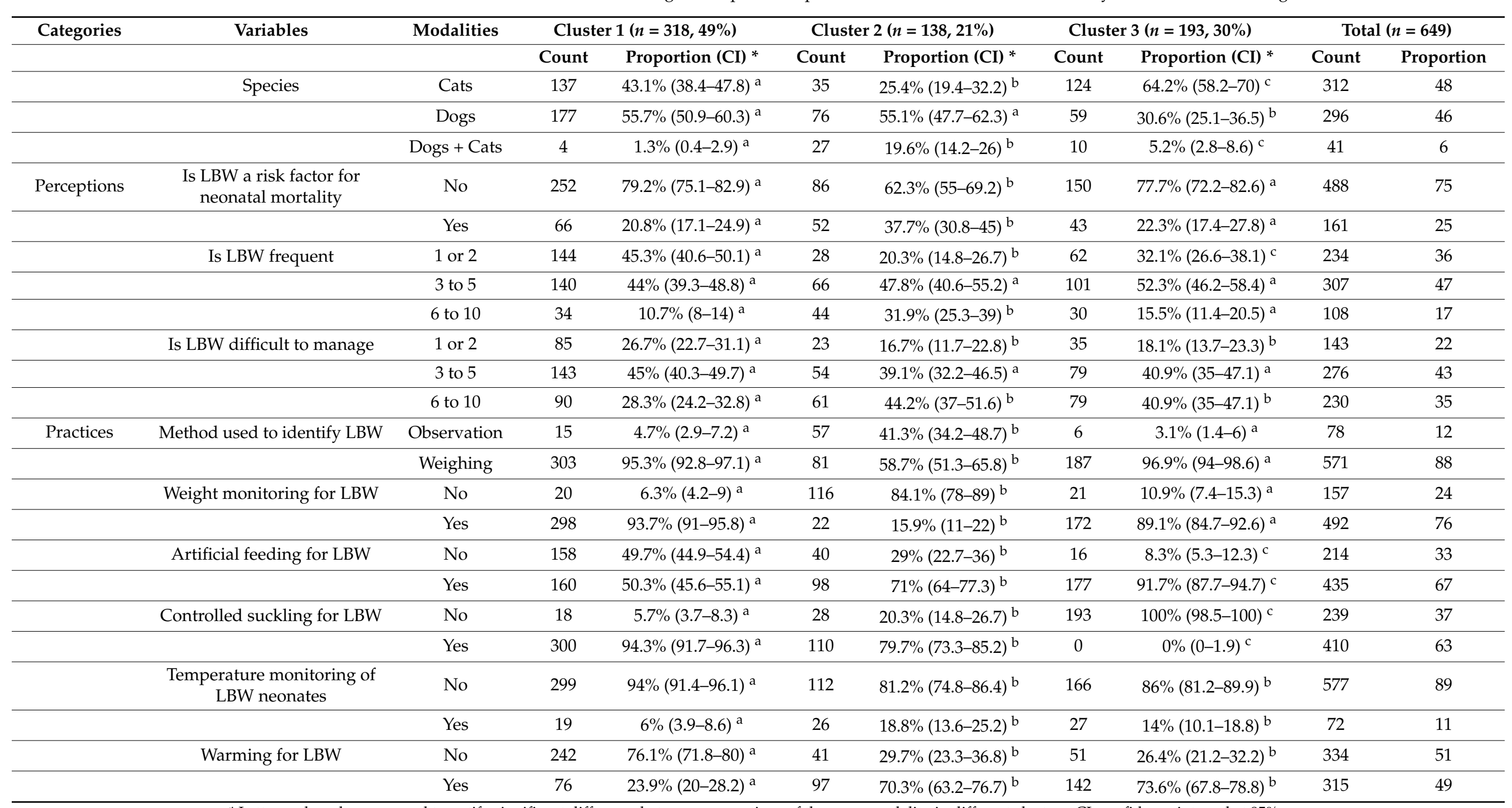

${ }^{*}$ Letters $\mathrm{a}, \mathrm{b}$ and $\mathrm{c}$ were used to notify significant difference between proportions of the same modality in different clusters. CI, confidence interval at $95 \%$. 
Breeders who gave a score of 1 or 2 on the frequency of LBW and the difficulty of managing it were significantly more numerous in Cluster 1 than in the other two (Table 3). Thus, breeders in Cluster 1 considered LBW to be less frequent and less difficult to manage than in the other clusters. Moreover, they frequently used controlled suckling and weighing, but they did not often warm up the LBW neonates.

Cluster 2 included breeders who estimated that LBW is a risk factor for neonatal mortality and who considered LBW as frequent. Moreover, the majority of breeders in this cluster did not use weighing, either at birth to identify LBW newborns or to monitor their weight evolution, were in Cluster 2. Mixed breeders were over-represented in this group.

Breeders in Cluster 3 considered LBW to be moderately frequent and difficult to manage. As in Cluster 1, they weighed LBW routinely. Among the three clusters, they practiced artificial feeding and warming most frequently, but never controlled suckling. Cat breeders were more likely to be represented in Cluster 3 (proportion significantly higher than in the two other clusters, Table 3).

\section{Discussion}

Despite the clear relationship between LBW and neonatal mortality [4-7], to the authors' knowledge, this work is the first to explore practices and perceptions of canine and feline breeders regarding LBW neonates. Knowing current practices is the first step towards targeting communication and teaching to improve them with the final objective of reducing puppy and kitten neonatal mortality.

Data were collected from 674 breeders. This population represents less than $2 \%$ of the total number of active breeders referenced in France (according to the Société Centrale Canine and the Livre Officiel des Origines Félines, LOOF [23]). Figure 1 shows that the respondents were distributed throughout France but in a heterogeneous way with a concentration of breeders around Paris and in the south of the country. This distribution is consistent with, on the one hand, the distribution of cat breeders detailed by LOOF [23] and, on the other hand, with that of dog breeders estimated using the data of the Breeding Management System software (BMS, Royal Canin SAS, Aimargues, France; $n=3027$ kennels; unpublished data). The respondents were recruited on a voluntary basis, mostly via Internet. Thus, a selection bias cannot be ruled out and younger breeders (more familiar with the Internet) and/or with more efficient management of LBW and/or already aware of LBW as an issue regarding neonatal mortality, were potentially more likely to respond to the survey. As this survey was written in French, the respondents were mostly French or from French-speaking countries. Further studies are needed to explore the differences in management and perceptions in other countries.

Perception regarding LBW neonates and their management varied between the different clusters (Table 3) but, surprisingly, only $25 \%$ of breeders estimated that LBW is a risk factor for neonatal mortality. There is thus a paradox considering scientific consensus on the subject [1,4-6]. The data reported in this study underline a lack of knowledge transfer from the scientific community to actors in the field (canine and feline breeders). Recognition of LBW as a health issue as well as its identification is indeed the first step towards improving management practices regarding these newborns $[24,25]$ and thus improving their survival.

With regard to management practices, the current analysis revealed three clusters all of which implement actions to manage LBW (Table 3). Canine and feline neonates, and more particularly those with LBW, are born with low energy reserves and are unable to produce heat and regulate their body temperature during their first days of life $[8,26]$. Adequate milk intake is thus crucial, and hypothermia will occur rapidly in the case of starvation. This condition can rapidly worsen as hypothermia depresses gut motility and decreases milk digestion, leading to suckling failure and sometimes bacterial translocation from the gut to the blood stream with sepsis and death as a consequence [8,27]. As expected, and as recommended in the literature $[4,7,28]$, weighing at birth and weight monitoring is a common practice in the kennels and catteries of this study $(88 \%$ and $76 \%$, 
respectively). Evaluation of weight is an easy-to-use tool, providing an immediate and objective result that allows identifying LBW neonates and controlling if weight gain is adequate. Cluster 2 included breeders who weighed significantly less, preferring to identify LBW by observation of neonate behaviour or body size. However, those breeders frequently implemented other recommended practices such as warming neonates and controlling feeding [29-31]. By doing so, they combat hypothermia and hypoglycemia, described as the major causes of neonatal mortality $[8,27,29]$. In Clusters 1 and 3 , breeders preferred to ensure an adequate energy supply through controlled suckling and artificial feeding, respectively. It is interesting to note that, in Cluster 3, artificial feeding did not seem to be associated with regular temperature monitoring, contrary to the recommendations (milk formula should be provided only in newborns with body temperature $>34^{\circ} \mathrm{C}$; Table 3) [30]. Lastly, canine, feline and mixed-species breeders were not equally distributed among the clusters (Table 3), suggesting that the species bred could be one of the determinants of the management practices implemented. Considering their crucial role, it could be interesting to determine the most important determinants of the management practices applied by the breeders.

Furthermore, it would be very useful to identify which practice is more or less effective in terms of managing LBW neonates, by comparing the clusters on the basis of their mortality rates. Unfortunately, the figures provided by the respondents were inconsistent and unusable for analysis, indicating that neonatal mortality is poorly estimated by canine and feline breeders; likewise for other domesticated species [32,33]. The calf mortality rate, for example, was underestimated by 20 to $50 \%$ of farmers, with $94 \%$ of them perceiving calf mortality as not being a problem [34]. The effectiveness of breeders' management regarding LBW survival cannot be evaluated without adequate recording of neonatal mortality at a large scale. Electronic data capture systems could be very useful tools for achieving this goal. Nevertheless, it will require strong motivation from the breeder to accurately record morbidities and mortalities.

\section{Conclusions}

This survey allowed us to identify three clusters of canine and feline breeders in terms of current LBW management practices. The management practices described by breeders were complementary in the three clusters and may have a beneficial impact on LBW survival, although the relationship between those practices and the survival of newborns remains to be established. Indeed, further studies are needed to develop practical guidelines to deal with LBW (to prevent and manage them) and thus improve puppies' and kittens' survival.

Supplementary Materials: The following are available online at https://www.mdpi.com/article/ 10.3390/ani11102953/s1, Table S1: questions used in the survey addressed to cat and dog breeders translated from French into English.

Author Contributions: Conceptualization, A.M., S.C., A.G. and H.M.; data curation, A.M. and H.M.; formal analysis, A.M., C.S., V.G., A.G. and H.M.; funding acquisition, S.C. and V.G.; investigation, A.M., S.C., A.G. and H.M.; methodology, A.M., S.C., C.S., V.G., A.G. and H.M.; project administration, A.M., S.C. and H.M.; supervision, S.C., C.S. and H.M.; visualization, A.M., S.C., C.S., A.G. and H.M.; writing—original draft, A.M., S.C., A.G. and H.M.; writing—review and editing, A.M., S.C., C.S., V.G., A.G. and H.M. All authors have read and agreed to the published version of the manuscript.

Funding: This study was partially funded by Royal Canin SAS (Aimargues, France). V.G. is Royal Canin SAS employee. There was no additional external funding received for this study.

Institutional Review Board Statement: Not applicable.

Informed Consent Statement: All the breeders were informed before completing the questionnaire that answering the questions was done on a voluntary basis. The breeders gave their informed consent for the scientific use of the data at the beginning of the questionnaire. 
Data Availability Statement: Data are available from the corresponding author (A.M.) on reasonable request.

Acknowledgments: The authors are grateful to Florine Guiraud and the fifteen breeders who helped in the construction of the questionnaire and also to Vincent Biourge for his useful comments. Thanks also go to all the breeders who kindly gave up their valuable time to complete the survey.

Conflicts of Interest: The authors have declared that no competing interests exist. V.G. participated in the analyses of the data, in the methodology and in the reviewing of the paper. The commercial affiliation does not interfere with the full and objective presentation of the results of this work.

\section{References}

1. Indrebø, A.; Trangerud, C.; Moe, L. Canine neonatal mortality in four large dog breeds. Acta Vet. Scand. 2007, 49, S1-S2. [CrossRef]

2. Fournier, A.; Masson, M.; Corbière, F.; Mila, H.; Mariani, C.; Grellet, A.; Chastant-Maillard, S. Epidemiological analysis of reproductive performances and kitten mortality rates in 5303 purebred queens of 45 different breeds and 28,065 kittens in France. Reprod. Domest. Anim. 2017, 52, 153-157. [CrossRef] [PubMed]

3. Chastant-Maillard, S.; Guillemot, C.; Feugier, A.; Mariani, C.; Grellet, A.; Mila, H. Reproductive performance and pre-weaning mortality: Preliminary analysis of 27,221 purebred female dogs and 204,537 puppies in France. Reprod. Domest. Anim. 2017, 52, 158-162. [CrossRef]

4. Mugnier, A.; Mila, H.; Guiraud, F.; Brévaux, J.; Lecarpentier, M.; Martinez, C.; Mariani, C.; Adib-Lesaux, A.; Chastant-Maillard, S.; Saegerman, C.; et al. Birth weight as a risk factor for neonatal mortality: Breed-specific approach to identify at-risk puppies. Prev. Vet. Med. 2019, 171, 104746. [CrossRef] [PubMed]

5. Mila, H.; Grellet, A.; Feugier, A.; Chastant-Maillard, S. Differential impact of birth weight and early growth on neonatal mortality in puppies. J. Anim. Sci. 2015, 93, 4436-4442. [CrossRef]

6. Groppetti, D.; Ravasio, G.; Bronzo, V.; Pecile, A. The role of birth weight on litter size and mortality within $24 \mathrm{~h}$ of life in purebred dogs: What aspects are involved? Anim. Reprod. Sci. 2015, 163, 112-119. [CrossRef]

7. Mugnier, A.; Lecourtois, C.; Mila, H.; Guiraud, F.; Mariani, C.; Adib-Lesaux, A.; Chastant-Maillard, S.; Grellet, A. Low birth weight as a risk factor for kitten mortality: Determination of breed-specific thresholds. In Proceedings of the 22nd Congress of European Veterinary Society for Small Animal Reproduction (EVSSAR), Berlin, Germany, 28 June 2019; p. 36.

8. Mila, H.; Grellet, A.; Delebarre, M.; Mariani, C.; Feugier, A.; Chastant-Maillard, S. Monitoring of the newborn dog and prediction of neonatal mortality. Prev. Vet. Med. 2017, 143, 11-20. [CrossRef] [PubMed]

9. Chastant-Maillard, S.; Mugnier, A.; Viaud, C.; Bonte, T.; Morin, A.; Grellet, A. Suckling behavior of puppies during the first 24 hours of life. In Proceedings of the 22nd Congress of European Veterinary Society for Small Animal Reproduction (EVSSAR), Berlin, Germany, 28 June 2019; p. 54.

10. Kirkden, R.D.; Broom, D.M.; Andersen, I.L. Invited review: Piglet mortality: Management solutions. J. Anim. Sci. 2013, 91, 3361-3389. [CrossRef]

11. Nowak, R.; Poindron, P. From birth to colostrum: Early steps leading to lamb survival. Reprod. Nutr. Dev. 2006, 46, 431-446. [CrossRef]

12. Hinch, G.; Brien, F. Lamb survival in australian flocks: A review. Anim. Prod. Sci. 2014, 54, 656. [CrossRef]

13. Elliott, J.; Sneddon, J.; Lee, J.A.; Blache, D. Producers have a positive attitude toward improving lamb survival rates but may be influenced by enterprise factors and perceptions of control. Livest. Sci. 2011, 140, 103-110. [CrossRef]

14. Santman-Berends, I.M.G.A.; Buddiger, M.; Smolenaars, A.J.G.; Steuten, C.D.M.; Roos, C.A.J.; Van Erp, A.J.M.; Van Schaik, G. A multidisciplinary approach to determine factors associated with calf rearing practices and calf mortality in dairy herds. Prev. Vet. Med. 2014, 117, 375-387. [CrossRef] [PubMed]

15. Vasseur, E.; Borderas, F.; Cue, R.I.; Lefebvre, D.; Pellerin, D.; Rushen, J.; Wade, K.M.; de Passillé, A.M. A survey of dairy calf management practices in Canada that affect animal welfare. J. Dairy Sci. 2010, 93, 1307-1316. [CrossRef] [PubMed]

16. Villettaz Robichaud, M.; de Passillé, A.M.; Pearl, D.L.; LeBlanc, S.J.; Godden, S.M.; Pellerin, D.; Vasseur, E.; Rushen, J.; Haley, D.B. Calving management practices on canadian dairy farms: Prevalence of practices. J. Dairy Sci. 2016, 99, 2391-2404. [CrossRef] [PubMed]

17. Beam, A.L.; Lombard, J.E.; Kopral, C.A.; Garber, L.P.; Winter, A.L.; Hicks, J.A.; Schlater, J.L. Prevalence of failure of passive transfer of immunity in newborn heifer calves and associated management practices on US dairy operations. J. Dairy Sci. 2009, 92, 3973-3980. [CrossRef] [PubMed]

18. Holmøy, I.H.; Kielland, C.; Marie Stubsjøen, S.; Hektoen, L.; Waage, S. Housing conditions and management practices associated with neonatal lamb mortality in sheep flocks in Norway. Prev. Vet. Med. 2012, 107, 231-241. [CrossRef] [PubMed]

19. Dohoo, I.R.; Ducrot, C.; Fourichon, C.; Donald, A.; Hurnik, D. An overview of techniques for dealing with large numbers of independent variables in epidemiologic studies. Prev. Vet. Med. 1997, 29, 221-239. [CrossRef]

20. Husson, F.; Le, S.; Pagès, J. Exploratory Multivariate Analysis by Example Using R; CRC Press: Boca Raton, FL, USA, 2017; ISBN 978-1-315-30186-0.

21. R Core Team. R: A Language and Environment for Statistical Computing; R Foundation for Statistical Computing: Vienna, Austria, 2016. 
22. Lê, S.; Josse, J.; Husson, F. FactoMineR: An R package for multivariate analysis. J. Stat. Softw. 2008, 25, 1-18. [CrossRef]

23. LOOF. Detailed LOOF Statistics per Breed. Available online: https://www.loof.asso.fr/stats/intro_stats-en.php\#eleveurs (accessed on 4 March 2021)

24. Kristensen, E.; Jakobsen, E.B. Challenging the myth of the irrational dairy farmer; understanding decision-making related to herd health. N. Z. Vet. J. 2011, 59, 1-7. [CrossRef]

25. Dwyer, C.M.; Conington, J.; Corbiere, F.; Holmøy, I.H.; Muri, K.; Nowak, R.; Rooke, J.; Vipond, J.; Gautier, J.-M. Invited review: Improving neonatal survival in small ruminants: Science into practice. Animal 2016, 10, 449-459. [CrossRef]

26. Grundy, S.A. Clinically relevant physiology of the neonate. Vet. Clin. N. Am. Small Anim. Pract. 2006, 36, 443-459. [CrossRef]

27. Münnich, A.; Küchenmeister, U. Causes, diagnosis and therapy of common diseases in neonatal puppies in the first days of life: Cornerstones of practical approach. Reprod. Domest. Anim. 2014, 49, 64-74. [CrossRef] [PubMed]

28. Groppetti, D.; Pecile, A.; Palestrini, C.; Marelli, S.; Boracchi, P. A national census of birth weight in purebred dogs in Italy. Animals 2017, 7, 43. [CrossRef] [PubMed]

29. Lawler, D.F. Neonatal and pediatric care of the puppy and kitten. Theriogenology 2008, 70, 384-392. [CrossRef] [PubMed]

30. Little, S. Playing mum: Successful management of orphaned kittens. J. Feline Med. Surg. 2013, 15, 201-210. [CrossRef] [PubMed]

31. Davidson, A.P. Neonatal resuscitation: Improving the outcome. Vet. Clin. N. Am. Small Anim. Pract. 2014, 44, 191-204. [CrossRef]

32. Vasseur, E.; Pellerin, D.; de Passillé, A.; Winckler, C.; Lensink, B.; Knierim, U.; Rushen, J. Assessing the welfare of dairy calves: Outcome-based measures of calf health versus input-based measures of the use of risky management practices. Anim. Welf. 2012, 21, 77-86. [CrossRef]

33. Kopp, K.; Hernandez-Jover, M.; Robertson, S.; Abuelo, A.; Friend, M. A survey of new south wales sheep producer practices and perceptions on lamb mortality and ewe supplementation. Animals 2020, 10, 1586. [CrossRef]

34. Vasseur, E.; Rushen, J.; de Passillé, A.M.; Lefebvre, D.; Pellerin, D. An advisory tool to improve management practices affecting calf and heifer welfare on dairy farms. J. Dairy Sci. 2010, 93, 4414-4426. [CrossRef] 